\title{
Rising to the level of a record? Some thoughts on records and documents
}

\section{Geoffrey Yeo}

[Pre-print of article published in Records Management Journal 21 no.1 (2011), 8-27]

According to American archival educator Richard Cox $(2001,1)$, 'most people have a sense about what makes something a record'. From South Africa, Verne Harris $(2001,39)$ has noted the same phenomenon, commenting sceptically that 'the notion that the concept of 'record' has a self-evident meaning remains resilient' in professional discourse. Roger Pédauque, a French information scientist, made similar comments about the concept of a 'document', observing that 'documents are ubiquitous. ... The concept is ... intuitive for all of us, and we do not feel the need to clarify it' (Pédauque 2003, 2).

These observations frequently ring true in the field of records management, where professionals have often been dismissive of attempts at conceptual analysis, preferring what they see as a 'no-nonsense' approach to getting on with the job and achieving results. A good example can be found in Kelvin Smith's book Public Sector Records Management, which takes an assertively pragmatic stance, advising its readers that 'there seems little point in dwelling on 'what is a record?' ... You know the answers to such questions and will want to get on and undertake records management' (K. Smith 2007b, ix). Unfortunately, it is far from clear that records managers know the answers to such questions; and if they seek elucidation in records management textbooks they will find that these rarely provide unambiguous guidance. Writers who discuss the meanings or perceived boundaries of terms such as 'record' offer a variety of interpretations, and those who consider such discussion unnecessary often have different tacit perceptions that underlie the advice they give.

Like 'record', the term 'document' is one of the mainstays of the records manager's vocabulary. According to an Australian textbook from the 1990s, 'a document is synonymous with the term 'record"' (P. A. Smith et al. 1995, 5). Few other writers or practitioners view the two terms as fully interchangeable, but most see close connections between them, albeit with considerable disagreement about precisely where the connections lie.

A thread on the RECMGMT-L listserv in May 2009 indicated the divergent views held by a number of practitioners in the USA. The debate was triggered by a question about the circumstances in which documents might be said to 'rise to the level of a record' - a phrase that acquired a short-lived notoriety some years ago during the so-called 'PROFS' case about preservation of White House e-mails, but seems never to have been fully explicated. Despite their differing opinions on how such a transformation might occur, most contributors to the discussion accepted the underlying notion that documents can be transmuted into records, but a minority disputed this premise and suggested that record status is inherent rather than achieved. The debate was inconclusive, and several contributors proposed that every organisation must reach its own definitions of 'document' and 'record'. Such diversity might be seen as emblematic of a dynamic profession open to multiple perspectives, but it is also arguable that uncertainty about fundamental concepts may constrain 
the profession's ability to adopt standards, share knowledge and engage in constructive dialogue with other communities.

This paper reviews some of the statements made about records and documents in English-language professional literature ${ }^{1}$ and offers some thoughts on the relationships between records and documents in digital and pre-digital environments and their intersections with other concepts such as 'data'. It examines notions that documents become records when they are 'declared', and suggests that these are problematic because the logical characteristics of documents differ from those of records.

\section{Records in documentary and non-documentary form}

A commonly held view is that 'all records are documents, but not all documents are records'. This quotation is from Trudy Peterson $(1991,193)$, but the same opinion has been expressed by Rick Barry $(1993,27)$ and Trevor Livelton $(1996,64)$, among others. The view that not all documents are records seems easy to accept. In our book Managing Records, Elizabeth Shepherd and I argued that 'blank forms, ... advertising posters and reference books are ... documents, but ... not records', and that documents such as picture postcards are only records if used to send a message (Shepherd and Yeo 2003, 13-14). Ken Thibodeau (2002, 30) expounded a similar argument when he wrote that 'what differentiates records from documentary materials in general is ... their connection to the activities in which they are made and received'.

But is it correct to say that all records are documents? Many writers and practitioners have thought so, and have characterised a record as 'a special kind of document' (Livelton 1996, 64). In a glossary published by the Society of American Archivists in 1992, a record was defined as 'a document created or received and maintained by an agency, organization or individual in pursuance of legal obligations or in the transaction of business' (Bellardo and Bellardo 1992, 28). Further definitions of a record as a kind of document can be found in works by Peter Emmerson $(1989,5)$ and Luciana Duranti $(2005,363)$.

In the era when documents were perceived as written or printed text on paper, such definitions may have been uncontroversial. They presented few difficulties even in the early days of computing, when a document could be defined as 'a named, structural unit of text that can be stored, retrieved and exchanged ... as a separate unit' (Roberts 1994, 19, citing the IBM Dictionary of Computing). In Michael Buckland's words $(1991,353)$, the term 'document' was 'normally used to denote texts or, more exactly, text-bearing objects'. However, Buckland is only one of many recent writers to acknowledge that documents need not be exclusively textual, that (for example) images and graphics can be incorporated into textual documents, and that images and graphics could be considered documents even if they are not embedded in text (Buckland 1991, 353; Roberts 1994, 19). Extending these ideas to audio and video appears more problematic. While some writers and practitioners seem happy with the notion of audiovisual 'documents', for others the term 'document' connotes media and formats that are, or are perceived as, twodimensional (Pockley 1995/2005; Pearce-Moses 2003). Similar uncertainty arises in legal contexts: civil evidence statutes tend to define 'documents' widely, encompassing sound and images; but according to Ian Walden $(1993,125)$ when considering the 'best evidence' rule courts have often held that 'films, tapes and video recordings are not to be regarded as documents'. Proliferation of media and 
rapid developments in information technology have left us unsure how far, if at all, multimedia objects or objects with embedded software can be called documents.

The archetypal record probably takes the form of a unit of text, more or less in narrative style, though possibly also containing graphics or images; few observers are likely to deny that records of this kind fall within the domain of documents. But most - probably all - records managers and archivists now recognise that records need not be inscribed text or static images, but could be (for example) voice recordings or moving films. An audiotape or film of a conference, a meeting or an interview is easily recognisable as a record of the event concerned.

Acknowledgement of such records may make it more difficult for us to define a record as a kind of document.

The difficulty grows larger if we accept that records can also take the form of threedimensional artefacts. In earlier ages the recording of activities and events using such artefacts was often commonplace. In 1838 a Delaware farm worker sued his employer for non-payment of wages and won his case; like many illiterate farmhands at that time, he kept a notched stick as a record of the work he had done, and the court admitted the stick as evidence, apparently relying on the principle - still followed in courts of law today - that 'regular entries made in the routine of business' constituted an admissible record (Fishbein 1982). Notched sticks and bones have a long history as a form of record. Archaeologists investigating hunter-gatherer societies in Africa and Europe have found notched animal bones more than twenty thousand years old, and these are sometimes thought to have been records kept by hunters of the number of kills they had made (Joseph 1991, 24). At a more sophisticated level, in medieval and post-medieval England, notched wooden tallies were used as financial receipts, with different sums of money recorded using notches of varying sizes and intervals. Tallies were split lengthwise to give each party an identical record, thus providing security against forgery or falsification. In the Exchequer their use continued until 1826; as is well known, a few years later when the tallies were ordered to be burnt the fire accidentally spread and destroyed the Houses of Parliament (Jenkinson 1911; Baxter 1994). ${ }^{2}$

An even more sophisticated example of recordkeeping using a three-dimensional artefact is the quipu, a type of knotted string device used by Inca rulers in preliterate South America to issue orders, convey messages and record tribute payments, inventories and population censuses. The Incas were able to record all these things using strings and clusters of knots, and although the precise recording system is not fully understood it probably employed the material, colour and construction of the strings, the number and directionality of the knots and their distance from a primary string, to serve purposes similar to those for which other cultures use writing (Urton 1998). The Spanish conquerors of South America admitted quipu records as evidence in their courts. When we consider such artefactual records that make no use of written text, we may wish to question how far definitions of a record as a kind of document merely reflect practices predominant in western cultures at particular periods of history.

\section{Documents and data}

In our own era, computing specialists often distinguish data from documents, and computer technology has introduced us to the possibility of maintaining and processing data using methods that are independent of documentary formats. In digital environments, documents are seen as the domain of word-processing and 
similar software, while data are usually associated with separate applications built around database technology.

The distinction between data and documents is sometimes presented as a distinction between structured and unstructured resources. Those who adopt this view characterise documents as 'unstructured text created in a non-repetitive manner', in contrast to data, defined as 'structured information created on a repetitive basis' (McDonald 1989, 7). Allusions to structured and unstructured information are common in computing magazines and websites (e.g. Blumberg and Atre 2003; Tyler 2003; Robb 2004; Dorion 2007) and sometimes find their way into the records management press, particularly in articles placed by software vendors. Writers who use this terminology often give examples, especially of 'unstructured' resources, which are frequently said to include memoranda, reports, correspondence and other 'narrative text', as well as images and graphics (McDonald 1989, 7; Tyler 2003, 27; Cimtech 2007, 12).

The notion that documents are unstructured is open to dispute, and I would argue that it is misleading. Creators of documents seek to convey meaning by imposing linear structures on the words, phrases, sentences and other components they employ. Although in a typical document few of the structural elements are formally labelled, the document's intelligibility derives from its internal structure and the relationships between the textual (and sometimes visual) elements of which it is composed. With databases, processing by users is normal and the utility of a dataset is independent of the order in which it is presented; but when we view documents they have been pre-packaged with an intention that they should be intelligible without further processing, and the ordering of their components is fundamental.

Before the advent of computing, textual records seemed inextricably tied to documentary formats, but the digital revolution has made the view that 'all records are documents' implausible. In many workplaces, entry of data into databases has superseded creation of documents as the preferred method of creating records. For example, staff working at a helpdesk may enter data such as names, dates and subjects of enquiry into a database and these data constitute the only record of the handling of the enquiries. As well as being used to create records of completed activities, what we might call 'data-centric' systems can also be employed to perform the activity itself. When we make a purchase on a website, or draw cash at an automatic teller machine, we enter data that are transmitted to the supplier to effect the transaction. Other customers submit similar though not identical data, and these data will form a record of customers' transactions that is independent of document constraints.

In the modern world, many commercial and governmental transactions are performed by transmitting data rather than documents, and increasing numbers of organisational records are created using data-centric systems. Most computer applications designed to support particular work processes or functions (sometimes referred to as business systems or transaction processing systems) are data-centric: much if not all of their capability derives from database technologies. Standalone systems for what are often called 'support' functions, such as finance and human resources management, became commonplace towards the end of the last century, but in many organisations have now been replaced by integrated Enterprise Resource Planning systems that aim to coordinate organisational planning and control data and link 'support' functions to data about 'core' functions such as manufacturing, sales and distribution. ${ }^{3}$ Systems of this kind normally rely on 
relational databases with large numbers of tables and frequently contain both dynamic and static data. Dynamic data are subject to regular updating to ensure their currency. If the system creates and maintains records of business transactions, these records will necessarily take the form of static data that are not subject to change. Sometimes, especially in simpler systems, such records may be stored within a single table of the database, but in more complex systems for corporate use each record is typically distributed across several tables. ${ }^{4}$

Responding to the recognition that transactional records can be found in database systems, some records professionals have sought to expand their definition of 'documents'. For example, the VERS project at the Public Record Office Victoria, Australia, affirmed that documents might include databases and datasets as well as reports, e-mails, web pages and CAD files (Public Record Office Victoria 1998, 14-15). Outside the records management domain, Jennifer Rowley and John Farrow $(2000,40)$ suggested that 'stored data in any form constitute a document', and others have gone much further. In the mid 20th century the European documentalists Paul Otlet and Suzanne Briet sought to enlarge the scope of 'documents' beyond all forms of written texts and promoted the notion that documents could be three-dimensional. Briet's most frequently quoted example was an antelope which, she claimed, was transformed into a document when taken to a zoo. These ideas have rarely been embraced in professional practice, but were publicised in the writings of Michael Buckland in the 1990s and have been increasingly cited in recent literature (Buckland 1991 and 1997; Tourney 2003; Lund 2009). Further arguments for extending the concept of 'document' to include multimedia and the like were adduced by David Levy in his book Scrolling Forward. Levy $(2001,26-7)$ wanted to locate documents within the world of artefacts, but argued that documents encompass any artefact 'to which we delegate the task of speaking for us'. Robert Martin $(2007,81)$ took this mode of thinking to its seemingly inevitable conclusion, suggesting that 'everything we collect is really a document'.

Collapsing of boundaries and insisting on greater latitude for concepts that were once more closely defined have become fashionable pastimes across many disciplines, not least among writers sympathetic to post-positivism. In our field these tendencies have been more prominent in the literature on archives than in writings about records management, but the trends are unmistakeable. Growing numbers of voices insist that concepts such as provenance and creatorship must be extended beyond their traditional limits (Bastian 2006; Nesmith 2006; Brothman 2006); records continuum theories seek to dissolve artificial boundaries between records and archives (McKemmish 1997; Upward 2000); and increasingly we are told that our notions of archives should be refigured to include oral traditions, ritual performances, art, literature or landscape, perhaps even that 'everything is [an] archive' (McKemmish et al. 2005, 152-3; Sassoon 2007, 41-3; Ketelaar 2002, 577). But as boundaries are demolished and concepts previously distinct are assimilated, this inclusiveness can bring its own problems. Difficulties certainly arise where 'documents' are concerned. If we broaden our interpretation of the term to embrace 'everything we collect', then not only is there a risk of stretching the concept to the point of meaninglessness or incoherence (Weinberger 1996), but we also lack a usable label for the more limited class of entities that we have conventionally called 'documents'.

Of course, documents and data are not unrelated. Digital documents can be stored in databases. Forms and other document-like objects can be used to capture data, data 
can be output from databases into formats that resemble documents, ${ }^{5}$ and Extensible Markup Language (XML) offers a bridge between document and data characteristics. Some writers envisage a continuum from free-form documents to highly-regularised data, with intermediate objects displaying varying degrees of explicit structure (Rao 2002, 15; Glushko 2005, 4). ${ }^{6}$

Nevertheless, separate labels for the categories of 'data' and 'documents' remain valuable. As Deborah Juhnke noted $(2003,36)$, 'fitting digital data into the conceptual framework of a document' can be 'particularly troublesome'. In the world at large many, perhaps most, conceptual categories have fuzzy boundaries, but this does not mean that concepts are shapeless or without significance. For example, the boundaries between colours are ill-defined; the colour spectrum is a continuum, linguistic divisions between red and orange are arbitrary, and we can identify no fixed point at which redness ceases; but it does not follow from this that the labels given to colours are worthless or that terms such as red and orange, blue and purple, lack meanings within a community of shared understanding (Taylor 2003, 3-4). Much the same can be said of the differentiation between documents and data. Even if these categories show tendencies to merge in the middle ground, they remain distinct at their extremes. ${ }^{7}$ In Daniel Pitti's words $(2005,15)$, this distinction is 'of more than theoretical interest', because documents and data are underpinned by different technologies, optimised to perform different functions. In the digital era, the nature of these underpinning technologies is crucial to the design and implementation of practical techniques for managing, preserving and using records.

Electronic records are not confined to the documentary types of the paper world, and records can no longer be seen merely as a subset of documents. Our profession has been slow to grasp the realities of data-centric records, but these are now being recognised, not least in the National Archives of Australia's Functional Specifications for Recordkeeping Functionality in Business Information Systems Software (2006), Philip Bantin's Understanding Data and Information Systems for Recordkeeping (2008), and the Principles and Functional Requirements for Records in Electronic Office Environments published by the International Council on Archives (ICA) in association with the Australasian Digital Recordkeeping Initiative (2008b). Principles and Functional Requirements was adopted by the International Standards Organization as ISO16175 in 2010. It is substantially derived from the work of the National Archives of Australia and includes a module devoted to records in 'business systems' that 'are generally concerned with structured data rather than ... documents' (International Council on Archives 2008a, 7).

I have argued elsewhere that professional perceptions of records are subject to what psychologists call prototype effects. Most conceptual categories have prototypes: composite mental mappings of typical features, or exemplars of typical category members, which we use in assessing members of a category. Prototypes are specific to time and place; in western culture at the start of the 21st century, our mental prototype of a 'record' is probably a written document, created for business purposes with some pretensions to objectivity, and maintained in a formal system (Yeo 2008a, 119-22, citing Rosch 1978). However, not all records match the prototype, and at present data-centric records are non-prototypical. We tend to associate data and databases with notions that 'the most important information is fresh-off-the-wire, real-time information ... that tells us what is happening somewhere or other right now' (Gelernter 2002, 230) - the kind of information that records emphatically do not provide - and until recently data-centric records have had a low profile in records management literature and professional practice. 
Prototype theory asserts that prototypes arise in any categories with heterogeneous membership. We assess members of a category in terms of their similarity to the prototype. Robins are closer to our mental prototype of 'birds' than penguins or emus and desk chairs are more typical of 'chairs' than barbers' chairs or rocking chairs. They have fewer characteristics untypical of the category as a whole and may be considered 'better' members of the category concerned (Rosch 1978, 36; Lakoff $1987,41)$. In much the same way, many professionals may consciously or unconsciously consider document-like records to be 'better' examples of records. Traditionally most records have been created in the form of documents, and this precedent still influences our mental prototype in the digital age. Records managers have often assumed that 'electronic document and records management' ('EDRM') is a single technology offering a full solution to the management of digital records, and many published guidelines such as the American DoD5015.02 standard and the first two editions of the European Model Requirements for the Management of Electronic Records (MoReq1 and MoReq2) have focused largely or exclusively on records in documentary form (Department of Defense 2007; European Commission 2002 and 2008). Similar perceptions underlay the assertion in the UK's E-government Policy Framework for Electronic Records Management that electronic document management and electronic records management 'are closely related functions which are rapidly converging' (UK Government 2001, 11). The strength of the prototype has often led records managers to overlook non-documentary formats and attribute the characteristics of documents to the whole universe of records.

\section{'Declaring' records}

Another perception commonly held by records managers is that the term 'record' should be restricted to materials designated for preservation or formally captured in a records management system. In the paper world, as guidance from the former Public Record Office stated $(1998,5)$, public sector organisations in the UK were 'familiar with the convention of registered files. Anything that goes 'on file' becomes a record.' The notion that 'papers' can be 'accepted' as records at the moment when they are placed on file is also found outside the UK, for example in the writings of Australian archivist Ian Maclean $(1962,129)$. More recently, in Canada, Luciana Duranti $(1997,216)$ has asserted that 'documents' are not records until the moment when they are 'set aside' and 'put into relation with other records'. In the USA, Stephen Page (2008) has claimed that documents become records when they are described on a retention schedule. According to the English archivist F. G. Emmison $(1964,2)$, 'a record ... is simply a generic term for any document that has been set aside for preservation'.

In contrast to the idea of 'rising' to the level of a record, which perhaps implies a gradual emergence, these notions all seem to suggest a single moment of transition. In the digital environment they have become associated with EDRM software applications, in which items previously labelled as 'documents' are 'declared' to be records by an operator, or perhaps by an automated process, at the point in their life when they are deemed to cease being volatile and are captured in an electronic records management system. The idea of 'declaring' records is underpinned by longestablished public sector practices of registration, and also by the 'domains' (or 'workspaces') model developed in the 1990s, in which organisational documents are allocated to personal, workgroup or corporate domains, but only those assigned to the corporate domain become 'part of the corporate record' (IESC Electronic Data Management Subcommittee 1995; Australian Public Service Commission 2007; 
K. Smith 2007a, 7). When this approach is followed in EDRM systems, the contents of documents are frozen at the point of declaration when the document formally passes into corporate control (ANSI/AIIM/ARMA TR48-2004; Cimtech 2007, 17; European Commission 2008, 63).

Promoters of this approach distinguish between documents and records in terms of the features needed to manage them. Management of 'documents' is usually said to require systems that support collaborative work, access permissions, workflow, version control, review and approval of drafts, and sharing of documents across an organisation; those declared as 'records' require additional features to support contextual linkages and rigorous management of classification and retention, and to prevent modification and uncontrolled deletion. It is widely assumed that by capturing them in a formal records management system the organisation will be able to protect the authenticity, reliability and integrity of the records. ${ }^{8}$

According to the UK E-government Policy Framework for Electronic Records Management, 'electronic records are documents which have been captured into a corporate classification and filing system' (UK Government 2001, 13). The second edition of the electronic records management Reference Document issued by the former Public Record Office $(2002,5)$ defined a record as 'a document which has been declared as a formal record, constituted of both format and metadata'. This definition was dropped from the third edition issued by The National Archives (2007, 20), but this third edition and its effective successor MoReq2 continued to base their advice on an assumption that records are documents that have been selected for capture and stabilisation. ${ }^{9}$ Yet this assumption gives rise to a number of difficulties, both theoretical and practical. Conceptually, for example, it seems questionable whether record status can or should depend on the outcome of a selection process. At a practical level, as Gary Johnston and David Bowen noted $(2005,132)$, the 'declaration' model presupposes that organisational workflows require only mutable 'documents' and that fixed records are separable from operational tasks, a supposition that 'does not reflect the way many organisations work'.

Of course, there is often a desire to distinguish work in progress (drafts and working papers) and informal communications from completed or formal business. An organisation may consider its formal records to have an 'official' role as evidence of its actions, a role that drafts, informal notes and casual messages may not have (State Records of South Australia 2008; Government of Alberta 2004). Few organisations need to manage every record with maximum rigour. Efficient records management normally requires decisions about which records should be captured in a controlled environment that aims to maintain their contextualisation and integrity, and which records can be less tightly overseen.

Obviously for practical purposes when speaking or writing about EDRM and other formal systems it is convenient to have a short label for 'digital object or objects captured within the system', but it is unfortunate that in the absence of any other label the EDRM community has appropriated the word 'record' to serve this purpose. Taken literally, the limitation of 'records' to those formally 'declared' in EDRM systems leads to some absurd conclusions: that minutes are not a record of a meeting until captured in an EDRM system; that representations of business activity held in databases, or in other formats that EDRM cannot easily accommodate, cannot be considered records; and that organisations (or individuals) not possessing an EDRM system can have no records at all. 
Even outside the EDRM arena, many professionals have wanted to limit the scope of 'records' to those designated or 'set aside' for secure preservation. However, the idea that record status depends on formal designation is not known to the courts. For legal purposes, all records (including drafts, intermediate versions, security and reference copies, and records that survive by accident rather than design) can be subject to discovery or disclosure. Indeed, litigants and their lawyers often seek out the least formal records - rough notes, casual messages, e-mails - since these are frequently thought to offer the most revealing insights into the events under dispute.

\section{Record concepts}

I believe that we will have a very weak concept of the record if we try to make it contingent on decisions about formal status, management or retention. Such decisions are dependent on the judgement of the people who make them and are necessarily fallible. Moreover, artificially limiting the definition of records to those captured in formal systems seems akin to defining diseases as conditions formally diagnosed by a doctor, or a criminal as someone who has been caught by the police. As Angelika Menne-Haritz $(2006,31)$ said, 'records are records independently of whether they are captured in a records management system or not'. They may cross what Barbara Reed $(2005,121)$ called 'thresholds of formality' at various points in their lives, but the crossing of these thresholds does not determine their status as records. A record does not change its nature merely because someone decides to select it for formal preservation.

The ISO15489 records management standard emphasises the importance of records capture and its attendant opportunities to garner metadata, but it does not claim that records are formed by an act of capture or declaration. The notion that documents become records when they are 'declared' is also absent from the ICA's Principles and Functional Requirements. Many, perhaps most, professionals who have explored record concepts more deeply have preferred to characterise records in terms of their connections to evidence, information, or both. ${ }^{10}$ Australian recordkeepers often emphasise evidence as a key characteristic and define records as evidence of business activities. Others, including the compilers of ISO15489, have followed Ira Penn et al. $(1994,4)$ in seeing records as a 'category of information'; the definition of records in ISO15489 ('Information created, received and maintained ... in pursuance of legal obligations or in the transaction of business', ISO15489-1: 2001, 3) has been widely quoted. ${ }^{11}$ I have suggested (Yeo 2007 and 2008b) that it can be helpful to see records as representations, and that evidence and information are among the affordances they can supply. All these interpretations indicate that records are distinguished by a special relationship to activities, events or what I have elsewhere called 'occurrents' (Yeo 2008a, 136) in business or daily life, not by acts of declaration or capture. Even uncaptured records, or those considered informal communications, or those that survive by happenstance, are representations of activities. ${ }^{12}$ Like all representations, they are imperfect; but despite their imperfection we can expect to use them to learn something about the activities they represent.

I have also suggested that it is helpful to characterise records as 'persistent' (Yeo $2007,337)$. Persistence means that records have the capacity to endure beyond the immediate circumstances which lead to their creation. In the paper world persistence is a characteristic of documents as well as records, but in digital environments documents may have only a fleeting existence. Unsaved documents in a computer's temporary memory, including 'virtual' documents created by electronic transaction 
systems in response to users' requests, will not survive beyond the circumstances of their creation unless conscious efforts are made to stabilise them in a fixed form or to ensure that they can be recreated whenever a future need arises. The persistence of an electronic record is to be found in its capacity for repeated presentation: more precisely, in the continuing possibility of using technological tools to retrieve its digital components, assemble them appropriately and present the resulting record to a user. ${ }^{13}$ But paper records (and wooden tally sticks) have a simpler mode of persistence because they do not depend on computer technology for their continuance. Irrespective of medium, characterising records as persistent seems preferable to notions that records are necessarily objects that have been 'set aside' or retained for special treatment.

One reason for choosing to set records aside or capture them in a structured system is to formalise their relationship with other records, to provide fuller evidence of closely related activities. We need not doubt that this is usually a highly desirable outcome. Nevertheless, the status of a record does not depend on its being held with others. A letter or an invoice is a record irrespective of whether it is kept with other records or stands alone. Chris Hurley (c.2004) cited the fictitious example of Robinson Crusoe's diary as a record that necessarily exists in isolation. Of course we could perceive Crusoe's multiple entries in his diary as multiple records, and the diary itself as the recordkeeping system in which he captured them; but even if he had made only one diary entry it would still be a record. M. T. Clanchy (1993, 99-100) noted that early medieval estate surveys, such as the kalendarium made for Abbot Samson of Bury St Edmunds, were single records intended to stand by themselves, and that, in England at least, 'the habit of making and keeping records of proceedings in continuous series' did not become widespread until the late 12 th or 13th century. Such examples reinforce our understanding that, in Hurley's words (c.2004, sec.5.02), a record 'derives its 'record-ness' from the bond it has with circumstance' - from the contexts of its creation - rather than its juxtaposition to other records. Of course, in current practice few records stand alone, and the association of related records that is achieved by capturing them in a plural system adds contextual wrapping that may be critical to their interpretation; but it is not a necessary condition of their 'record-ness'.

\section{Documents and records: different logics}

Some writers have claimed that 'the world of business and government is based around documents' (Cimtech 2007, 12), and even if we think this an exaggeration we may accept that documents are omnipresent. But I would argue that documents and records follow different logics. Documents are defined by their format, records by their connection to activities, events or other temporal occurrents. Our notions of a document permit some ambiguity in terms of revisions and versions (when we edit a document we might be uncertain whether we have created a new document or a revised version of the same document); but this ambiguity may appear to be absent from the concept of record (according to AS4390.3-1996, sec.8.2.4, each revision creates a new record). ${ }^{14}$

Documents are normally perceived as entities at a single level, ${ }^{15}$ but records cannot be wholly identified with single physical or digital objects, and can exist at collective as well as unitary levels. A record may comprise a single document, but a part of a document might also be a record. For example, a record in a paper-based accounting system might be an entry or a sequence of entries in a ledger. Several documents can constitute a single record: as suggested in the report of the VERS project, the contents 
of a single record in a government context might be 'a Ministerial briefing note, ... a draft letter for the Minister to sign, and (possibly) supporting documentation' (Public Record Office Victoria 1998, 14). ${ }^{16}$ If an annotation on a document represents a later step within an activity (such as a note on an application form approving or rejecting the application) or a later activity (such as a modern annotation on an ancient deed stating that the annotator bought it at an auction sale), the annotation can also be seen as a record in its own right. ${ }^{17}$

Although many practitioners use the term 'record' to refer to objects at item level, there need not be simple one-to-one correspondences between records and physical or digital items or documents. ${ }^{18}$ In the world of data-centric records, where documentary notions are largely inapplicable and records are likely to be distributed across the tables of a database, the idea of a straightforward correspondence between 'record' and 'item' is even less helpful. At higher levels of aggregation, a series often comprises large numbers of records at lower levels, but it too can be seen as a single record, a representation of a work process. ${ }^{19}$

When the concept of record is understood in this way, records and documents are seen to be different kinds of entity, dancing to different tunes. Objects or sets of objects that are not in documentary format can be records, and lower-level records are the building blocks from which records at higher levels are constructed.

\section{Conclusion}

According to Jeff Morelli $(1993,84)$, 'a record is an entity which must be designated ... by a human being'. In the recent discussion on RECMGMT-L, Jesse Wilkins (2009) stated more bluntly that 'it ain't a record until someone says it is'. If these writers meant that record status depends on capture or control decisions made by individuals or teams of individuals, I must beg to disagree. It is not enough to say that the key to an understanding of the record lies in selecting certain documents to be records, or to claim that 'the distinguishing factor that makes records records is that they are managed in a particular way' (Reed 2005, 102). Both records and documents are richer and more intricate concepts than these simple models allow.

Underlying this debate is a simple question: when does a record come into existence? Over the last two decades, the view that record status is independent of management procedures has come to be associated with postcustodialist thinking and the Australian continuum model, while the view that records exist only when registered or declared is often associated with (among others) the work of Luciana Duranti and the InterPARES project. However, it is not necessary to reject custodial practice, or to agree with continuum theorists' views about the near-identity of records and archives, in order to perceive that records are characterised by relationships to actions and events rather than by human decisions about their disposition.

Records managers commonly have to obtain decisions about which records should be subject to formalised control systems, and which records can be handled less rigorously or summarily destroyed; but they do not have to restrict the label, or the concept, of 'record' to those designated for maximum protection or longer-term survival. However convenient it may be for records managers to assert that 'a record is what we decide to treat as a record', such notions will surely bemuse most people outside the world of records management and create unnecessary obstacles for the profession as it seeks to engage with the wider world. 
\{Fig.1, from Schoolcraft, Archives of Aboriginal Knowledge (1860)\}

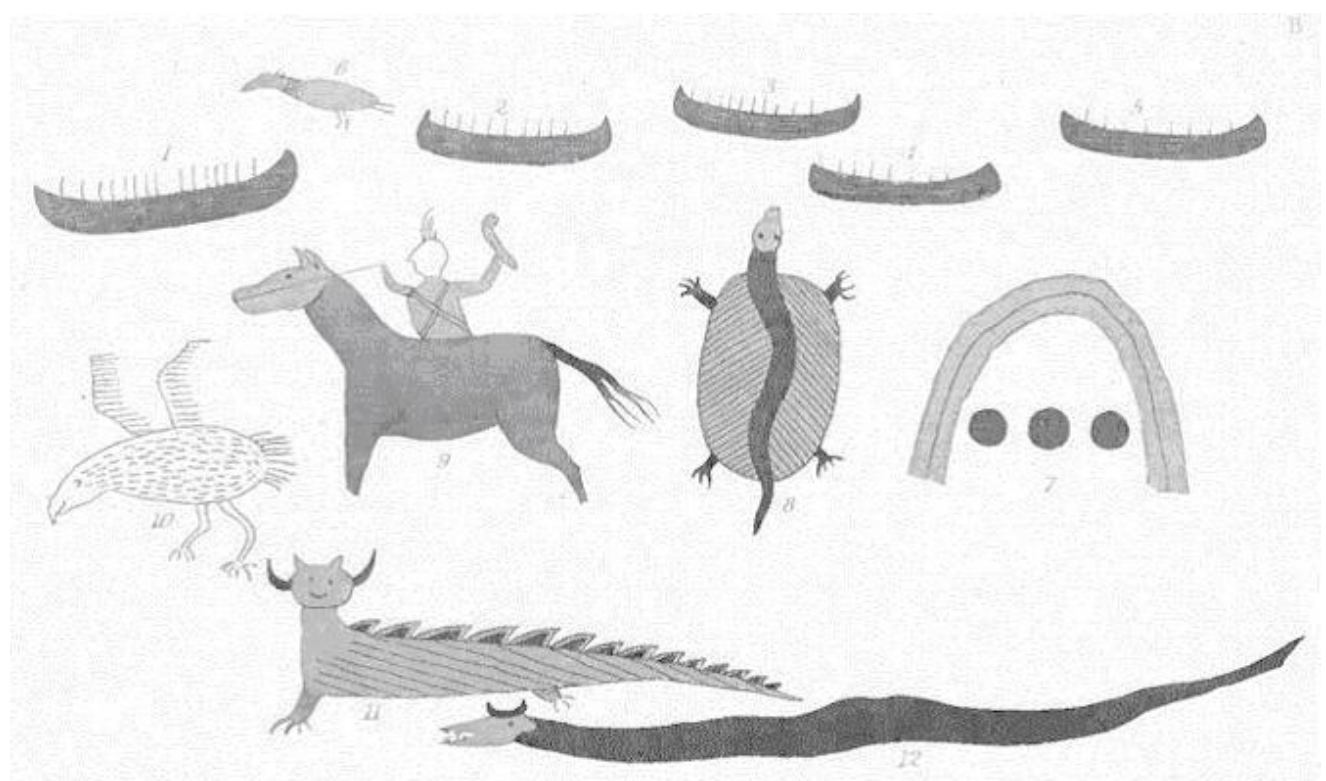

Nevertheless, there are senses in which records and record status depend on humans. Most obviously, records are created because someone decides to create them, gives orders for their creation or designs systems that create them automatically in the course of business. Human dependencies also intervene retrospectively. The capacity of records to represent activities depends on recognition of the representational conventions used by their creators, and later individuals may be unable to recognise what a given record represents or unwilling to agree that it is a record. We can easily see this if we look back from our 21stcentury vantage point to the world of preliterate recordkeeping. Figure 1 shows a petrogram (rock drawing) found in Michigan near Lake Superior; it depicts, among other things, a tortoise, five canoes and a man (apparently a warrior chief) on horseback. Some commentators believe this is a record of an expedition across the lake, but others offer different interpretations (R. Harris 1995, 74-5). Perhaps it is a record of something else, or perhaps it is not a record at all. We cannot tell, because we no longer fully understand the representational conventions of the Ojibwa people who made the drawing. But we can assume that a previous generation of Ojibwa society would have had no such difficulties. Regardless of whether representations are pictorial or textual they will be open to different interpretations, but within a single community the range of interpretation is likely to be limited; the members of a community share customs, beliefs and perceptions that enable degrees of common understanding and allow records to function as they do.

In organisational contexts, capture also has a role to play. Human decisions to capture records - and decisions to implement records management programmes that promote capture - assist in securing records against loss, damage, alteration or premature destruction. Systematic capture of records helps to ensure their accessibility and may add critical contextual safeguards that would otherwise be lacking. Systematic capture can also support the realisation of high-level records representing broad organisational functions and processes. Capture does not determine record status, but if capture systems are robust they allow the power of the record to be harnessed to the fullest possible extent. 
1 The perspectives of writers in other languages may not be directly comparable to those of English speakers, both because of the absence of a word corresponding to 'records' in many European languages and because of the differing nuances of words such as documenti and documentos in different linguistic and cultural traditions. For example, diplomatic scholars in civil law countries have often defined documents as 'written evidence... of facts having a juridical nature' (Duranti 1998, 43-4), thus giving this term a distinctly legal connotation that it rarely has in English usage. Full discussion of usages in other languages lies beyond the scope of this paper.

2 Tallies are usually associated with the English Exchequer, but in medieval times were widely used elsewhere. Surviving tallies normally bear handwritten annotations but, like the Delaware farmhand's stick, earlier ones presumably did not. Tallies are known to have been used in many European countries and Marco Polo reported that they were employed in non-literate financial transactions in 13th-century China (Baxter 1994, 201).

3 'Core' functions can be defined as those that are central to an organisation's purposes and relate directly to external customers; 'support' functions have only internal customers and relate to internal operations (Earl 1996, 61-7). For Enterprise Resource Planning systems, see Monk and Wagner (2009). Some are able to create or provide access to documents, but all are data-centric in the sense that they are primarily designed to capture, manage and manipulate data.

${ }^{4}$ I use the word 'record' in the sense familiar to readers of this journal. Records managers will be aware that database designers use 'record' with a different meaning.

${ }^{5}$ Data may be output as 'virtual' documents lacking long-term persistence, but can also be output as paper documents, as microform or as persistent digital objects, all of which offer recordkeeping potential. See Johnston and Bowen (2005) and Bantin (2008, 119-26), who recommend capture and preservation of persistent digital objects output by data-centric systems.

${ }^{6}$ Some writers (e.g. Tyler 2003) posit a third category comprising 'semi-structured' objects such as invoices, which they differentiate from 'structured' data and 'unstructured' documents; but these categories appear to lack distinct boundaries.

7 The same phenomenon is observable in other fields. For example, in their study of cartographic history, Delano-Smith and Kain $(1999,1)$ noted that maps are generally distinguished from pictorial views, but also indicated a fluid middle ground between the two, where no firm boundaries can be drawn. See also Labov (1973); McCloskey and Glucksberg (1978).

8 Differences, real or alleged, between the management of (electronic) documents and records are tabulated in ANSI/AIIM/ARMA TR48-2004; K.Smith (2007a, 57-8); European Commission (2008, 109).

${ }_{9}$ MoReq2 acknowledges the possibility that records may exist in the form of 'structured data' (European Commission 2008, 12) and, like The National Archives (2007, 20), MoReq2 has altered its formal definition of records. MoReq1 defined a record as a kind of 'document', but MoReq2 abandoned this in favour of the ISO15489 definition of records as a kind of 'information' (European Commission 2008, 17). But the shift in definition was not accompanied by a shift in the emphasis on documents in MoReq2's recommendations. At the time of writing, a consultation exercise was under way regarding a third edition of MoReq (tentatively labelled MoReq2010), which may adopt a different stance.

${ }^{10}$ In Yeo (2007, 319-31), I offered an overview of different ways in which records managers and archivists have interpreted relationships between records, evidence and information.

${ }_{11}$ The full definition in ISO15489-1 is 'Information created, received and maintained as evidence and information by an organization or person, in pursuance of legal obligations or in the transaction of business'. Aspects of this definition are open to question, not only for the reasons discussed in Yeo (2007, 326-9), but also because of the circularity of its allusion to 'information... maintained as... information'. However, it has been cited with increasing frequency in recent years, doubtless because it has carried the cachet of ISO approval.

12 Cf. the assertion by Stuckey $(1995,121)$, in his discussion of 'ephemeral' records, that 'despite [their] very short life they have been a record - evidence - that somebody did something'.

13 Of course, questions about how far standard computing environments can be relied on to ensure such persistence, how far the keeping of records requires additional measures, and what these measures should be, are not yet fully resolved. As the InterPARES project noted (Duranti and Thibodeau 2006), long-term preservation of records distributed across database tables, and of many electronic records in the form of compound documents, is more challenging than preserving single digital objects, because additional processing is required to assemble and interpret each record's digital components.

${ }^{14}$ Fresko (2007) noted that 'in the real world many people think in terms of versions of a record', but that MoReq1 and MoReq2 are 'underpinned by the concept that there is only one version of any record'.

15 Perceptions of documents as unitary entities may not be wholly correct. Intellectually, documents have components such as clauses, sentences, paragraphs and sections. Physically, what is perceived as a single document may be composed of several parts: digital documents may comprise a number of distinct bitstreams and paper documents forming an intellectual unity may extend across more than one sheet of paper. Nevertheless, the equation of a document with a single item or object remains potent, not least because users can normally engage with its components only by accessing the document as a whole. 
${ }^{16}$ Cf. Public Record Office [UK] $(1999,13)$, which stated that 'each record can comprise one or several documents', and the similar statement in MoReq2 (European Commission 2008, 176). In Managing Records Shepherd and I suggested that records can be identified with aggregations at numerous different levels (Shepherd and Yeo 2003, 65). In our model, records are not confined to item level, or to a level comprising a small group of items, but can exist at any level of aggregation; the levels are determined by relationships to occurrents. Understandings that records exist at multiple levels were also explicated in the Australian SPIRT project (McKemmish et al. 1999, 14), and underpin much other Australian work on recordkeeping.

${ }^{17}$ In the InterPARES project, annotations were defined as 'additions made to a record after it has been created' (Duranti and Thibodeau 2006, 18). I argue for a richer view: that annotations representing separate activities and steps are records in themselves. For example, approving applications by annotating existing documents creates records of the approval; a decision to create such records by annotation rather than by drawing up new documents is merely a matter of administrative convenience. Similar arguments apply to many of the examples given by Duranti and Thibodeau: annotations noting transmission, receipt or subsequent action can be seen as records of those events. Documents bearing annotations that represent multiple steps in an activity should be perceived as aggregate rather than elementary records. 18 Suggestions (e.g. in Horsman 1999) that 'items' or 'documents' can be equated with 'records' seemingly lack awareness that, unlike 'item' and 'document', 'record' is a relational term: a record is a record of some activity, process or other occurrent. Of course, a letter or report is both a document (in terms of its format) and a record (in terms of its representation of one or more activities). It was presumably this duality that led some commentators to claim that 'record' and 'document' are interchangeable terms. 19 For a further account of aggregate records, see Yeo (2008a, 132-8). I offer a fuller and more nuanced discussion in a paper provisionally entitled "Bringing things together: aggregate records in a digital age", to be submitted to Archivaria.

ANSI/AIIM/ARMA TR48-2004, Framework for Integration of Electronic Document Management Systems and Electronic Records Management Systems.

AS4390-1996, Records Management.

Australian Public Service Commission (2007), Note for File: a Report on Recordkeeping in the Australian Public Service, Case Study of the Australian Bureau of Statistics,

http://www.apsc.gov.au/mac/noteforfilecasestudiesabs.htm.

Bantin, P.C. (2008), Understanding Data and Information Systems for Recordkeeping, Facet, London. Barry, R.E. (1993), "Addressing electronic records management in the World Bank", in Hedstrom, M. (Ed.), Electronic Records Management Program Strategies, Archives and Museum Informatics, Pittsburgh. Bastian, J.A. (2006), "Reading colonial records through an archival lens: the provenance of place, space and creation", Archival Science, Vol.6 Nos.3-4, pp.267-84.

Baxter, W.T. (1994), "Early accounting: the tally and the checker-board", in Parker, R.H. and Yamey, B.S. (Eds.), Accounting History, Clarendon Press, Oxford.

Bellardo, L.J. and Bellardo, L.L. (1992), A Glossary for Archivists, Manuscript Curators, and Records Managers, Society of American Archivists, Chicago.

Blumberg, R. and Atre, S. (2003), "The problem with unstructured data", Information Management Magazine, February, http://www.information-management.com/issues/20030201/6287-1.html. Brothman, B. (2006), "Archives, life cycles, and death wishes: a helical model of record formation", Archivaria, Vol.61, pp.235-69.

Buckland, M.K. (1991), "Information as thing", in Journal of the American Society for Information Science, Vol.42 No.5, pp.351-60.

Buckland, M.K. (1997), "What is a document?", in Journal of the American Society for Information Science, Vol.48 No.9, pp.804-9.

Cimtech (2007), Managing Information and Documents: the Definitive Guide, 18th edn, Information Age, London.

Clanchy, M.T. (1993), From Memory to Written Record: England 1066-1307, 2nd edn, Blackwell, Oxford. Cox, R.J. (2001), Managing Records as Evidence and Information, Quorum, Westport.

Delano-Smith, C. and Kain, R.J.P. (1999), English Maps: A History, British Library, London.

Department of Defense [USA] (2007), Electronic Records Management Software Applications Design Criteria Standard, http://jitc.fhu.disa.mil/recmgt/p50152stdapr07.pdf.

Dorion, P. (2007), What is Unstructured Data and How is it Different from Structured Data in the Enterprise?, http://searchstorage.techtarget.com/generic/0,295582,sid5_gci1249073,00.html.

Duranti, L. (1997), "The archival bond", Archives and Museum Informatics, Vol.11 Nos.3-4, pp.213-18. Duranti, L. (1998), Diplomatics: New Uses for an Old Science, Scarecrow Press, Lanham.

Duranti, L. (Ed.) (2005), The Long-Term Preservation of Authentic Electronic Records: Findings of the InterPARES Project, Archilab, San Miniato.

Duranti, L. and Thibodeau, K. (2006), "The concept of record in interactive, experiential and dynamic environments: the view of InterPARES", Archival Science, Vol.6 No.1, pp.13-68. 
Earl, M.J. (1996), "Business process re-engineering: a phenomenon of organization", in Earl, M.J. (Ed.), Information Management: the Organizational Dimension, Oxford University Press, Oxford.

Emmerson, P. (Ed.) (1989), How to Manage your Records: a Guide to Effective Practice, ICSA, Cambridge. Emmison, F.G. (1964), Introduction to Archives, BBC, London.

European Commission (2002), Model Requirements for the Management of Electronic Records, Office for Official Publications of the European Communities, Luxembourg.

European Commission (2008), Model Requirements for the Management of Electronic Records, 2nd edn, Office for Official Publications of the European Communities, Luxembourg.

Fishbein, M.H. (1982), "The evidential value of non-textual records: an early precedent", American

Archivist, Vol.45 No.2, pp.189-90.

Fresko, M. (2007), E-mail to records-management-uk listserv, 14 December.

Gelernter, D. (2002), "Tapping into the beam", in Brockman, J. (Ed.), The Next Fifty Years, Weidenfeld \& Nicolson, London.

Glushko, R. (2005), Modeling Methods and Artifacts for Crossing the Data/document Divide, http://www.idealliance.org/proceedings/xml05/ship/34/GlushkoXML2005.pdf.

Government of Alberta (2004), Official and Transitory Records: A Guide for Government of Alberta Employees, http://www.im.gov.ab.ca/publications/pdf/OfficialTransitoryRecordsGuide.pdf.

Harris, R. (1995), Signs of Writing, Routledge, London.

Harris, V. (2001), "Law, evidence and electronic records: a strategic perspective from the global

periphery", Comma, 2001.1-2, pp.29-43.

Horsman, P. (1999), Archival Description from a Distant View,

http://www.asap.unimelb.edu.au/asa/stama/conf/WWKTranscript.htm.

Hurley, C. (c.2004), Relationships in Records,

http://www.sims.monash.edu.au/research/rcrg/publications/relationships-in-records-rev-3b.rtf.

IESC Electronic Data Management Subcommittee (1995), Improving Electronic Document Management: Guidelines for Australian Government Agencies, Office of Government Information Technology, Canberra. International Council on Archives (2008a), Exposure Draft of Principles and Functional Requirements for Records in Electronic Office Environments, Module 3: Guidelines and Functional Requirements for Records in Business Systems,

http://www.ica.org/sites/default/files/ICA\%20functional\%20requirements\%20draft\%20v0\%208.pdf.

International Council on Archives (2008b), Principles and Functional Requirements for Records in

Electronic Office Environments, Module 3: Guidelines and Functional Requirements for Records in Business Systems, http://www.ica.org/sites/default/files/ICA-Guidelines-

Principles\%20and\%20Functional\%20Requirements\%20Module\%203.pdf.

ISO15489-1:2001, Information and Documentation: Records Management. Part 1: General.

Jenkinson, H. (1911), "Exchequer tallies," Archaeologia, Vol.62, pp.367-80.

Johnston, G.P. and Bowen, D.V. (2005), "The benefits of electronic records management systems: a general review of published and some unpublished cases", Records Management Journal, Vol.15 No.3, pp.131-40.

Joseph, G.G. (1991), The Crest of the Peacock: Non-European Roots of Mathematics, I.B. Tauris, London. Juhnke, D.H. (2003), "Electronic discovery in 2010", Information Management Journal, Vol.37 No.6, pp.34-42.

Ketelaar, E. (2002), "The archive as a time machine", in Proceedings of the DLM-Forum 2002, Barcelona, 6-8 May 2002, Office for Official Publications of the European Communities, Luxembourg.

Labov, W. (1973), "The boundaries of words and their meanings", in Bailey, C-J.N. and Shuy, R.W. (Eds.), New Ways of Analyzing Variation in English, Georgetown University Press, Washington.

Lakoff, G. (1987), Women, Fire, and Dangerous Things: What Categories Reveal about the Mind, University of Chicago Press, Chicago.

Levy, D.M. (2001), Scrolling Forward: Making Sense of Documents in the Digital Age, Arcade, New York. Livelton, T. (1996), Archival Theory, Records and the Public, Scarecrow Press, Lanham.

Lund, N.W. (2009), "Document theory", Annual Review of Information Science and Technology, Vol.43, pp.399-432.

McDonald, J. (1989), "Records management and data management", Records Management Journal, Vol.1 No.1, pp.4-11.

Maclean, I. (1962), "An analysis of Jenkinson's Manual of Archive Administration in the light of Australian experience", in Hollaender, A.E.J. (Ed.), Essays in Memory of Sir Hilary Jenkinson, Society of Archivists, London.

Martin, R.S. (2007), "Intersecting missions, converging practice", RBM: A Journal of Rare Books, Manuscripts, and Cultural Heritage, Vol.8 No.1, pp.80-8.

McCloskey, M.E. and Glucksberg, S. (1978), "Natural categories: well-defined or fuzzy sets?", Memory and Cognition, Vol.6 No.4, pp.462-72.

McKemmish, S. (1997), Yesterday, Today and Tomorrow: A Continuum of Responsibility, http://www.sims.monash.edu.au/rcrg/publications/recordscontinuum/smckp2.html.

McKemmish, S., Acland, G., Ward, N. and Reed, B. (1999), "Describing records in context in the continuum: the Australian Recordkeeping Metadata Schema", Archivaria, Vol.48, pp.3-43. 
McKemmish, S., Gilliland-Swetland, A. and Ketelaar, E. (2005), "Communities of memory: pluralising archival research and education agendas", Archives and Manuscripts, Vol.33 No.1, pp.146-74.

Menne-Haritz, A. (2006), "Managing and archiving administrative records in the digital era: the instrumentality of electronic records for administrative communication", in Bütikofer, N., Hofman, H. and Ross, S. (Eds.), Managing and Archiving Records in the Digital Era: Changing Professional Orientations, Hier und Jetzt, Baden.

Monk, E. and Wagner, B. (2009), Concepts in Enterprise Resource Planning, 3rd edn, Course Technology, Boston.

Morelli, J.D. (1993), "Defining electronic records: a terminology problem or something more", in Ross, S. and Higgs, E. (Eds.), Electronic Information Resources and Historians: European Perspectives, Scripta Mercaturae Verlag, St Katharinen.

National Archives [UK] (2007), Requirements for Electronic Records Management Systems 3: Reference Document,

http://collections.europarchive.org/tna/20080107231552/http://www.nationalarchives.gov.uk/documents /revised-reference-document-v2.pdf.

National Archives of Australia (2006), Functional Specifications for Recordkeeping Functionality in Business Information Systems Software, http://www.naa.gov.au/Images/BISspecifications_tcm2-1014.pdf.

Nesmith, T. (2006), "The concept of societal provenance and records of nineteenth-century AboriginalEuropean relations in western Canada: implications for archival theory and practice", Archival Science, Vol.6 Nos.3-4, pp.351-60.

Page, S. (2008), Records Management: When Does a Document Become a Record?,

http://ezinearticles.com/?Records-Management-When-Does-a-Document-Become-a-Record?\&id=1086110. Pearce-Moses, R. (2003), The Language of Archives: Essence and Identity, http://rpm.lib.az.us/papers/LanguageOfArchives.pdf.

Pédauque, R.T. (2003), Document: Form, Sign and Medium, as Reformulated for Electronic Documents, http://archivesic.ccsd.cnrs.fr/docs/00/06/22/28/PDF/sic_00000594.pdf.

Penn, I.A., Pennix, G. and Coulson, J. (1994), Records Management Handbook, 2nd edn, Gower, Aldershot. Peterson, T.H. (1991), "An archival bestiary", American Archivist, Vol.54 No.2, pp.192-205.

Pitti, D. (2005), "Technology and the transformation of archival description", Journal of Archival Organization, Vol.3 Nos.2-3, pp.9-22.

Pockley, S. (1995, last updated 2005), Killing the Duck to Keep the Quack, http://www.duckdigital.net/FOD/FOD0055.html.

Public Record Office [UK] (1998), Guidelines for Management and Appraisal of Electronic Records, Public Record Office, London.

Public Record Office [UK] (1999), Functional Requirements for Electronic Records Management Systems 2: Reference Document, http://collections.europarchive.org/tna/20080107231552/http://www.nationalarchives.gov.uk/documents /reference.pdf.

Public Record Office [UK] (2002), Requirements for Electronic Records Management Systems 3: Reference Document,

http://collections.europarchive.org/tna/20080107231552/http://www.nationalarchives.gov.uk/documents /referencefinal.pdf.

Public Record Office Victoria (1998), Victorian Electronic Records Strategy Final Report, http://www.prov.vic.gov.au/vers/pdf/final.pdf.

Rao, R. (2002), "The secret of unstructured data", E-doc Magazine, Vol.16 No.5, pp.14-15.

Reed, B. (2005), "Records", in McKemmish, S., Piggott, M., Reed, B. and Upward, F. (Eds.), Archives:

Recordkeeping in Society, Charles Sturt University, Wagga Wagga.

Robb, D. (2004), Getting the Bigger Picture: Dealing with Unstructured Data,

http://www.enterpriseitplanet.com/storage/features/print.php/3407161.

Roberts, D. (1994), "Defining electronic records, documents and data", Archives and Manuscripts, Vol.22 No.1, pp.14-26.

Rosch, E. (1978), "Principles of categorization", in Rosch, E. and Lloyd, B.B. (Eds.), Cognition and

Categorization, Lawrence Erlbaum, Hillsdale.

Rowley, J. and Farrow, J. (2000), Organizing Knowledge, 3rd edn, Gower, Aldershot.

Sassoon, J. (2007), "Sharing our story: an archaeology of archival thought", Archives and Manuscripts, Vol.35 No.2, pp.40-54.

Schoolcraft, H.R. (1860), Archives of Aboriginal Knowledge, Vol.1, Lippincott, Philadelphia.

Shepherd, E. and Yeo, G. (2003), Managing Records, Facet, London.

Smith, K. (2007a), Planning and Implementing Electronic Records Management, Facet, London.

Smith, K. (2007b), Public Sector Records Management, Ashgate, Aldershot.

Smith, P.A., Siller, J., Poynton, T. and Exon, M. (1995), Introduction to Records Management, Macmillan, Melbourne.

State Records of South Australia (2008), Adequate Records Management in Perspective: Creating Official Records, http://www.archives.sa.gov.au/files/management_ARM_creating.pdf. 
Stuckey, S. (1995), "The Australian Archives' policy on electronic records", in Playing for Keeps: The Proceedings of an Electronic Records Management Conference Hosted by the Australian Archives, Australian Archives, Canberra.

Taylor, J.R. (2003), Linguistic Categorization: Prototypes in Linguistic Theory, 3rd edn, Oxford University Press, Oxford.

Thibodeau, K. (2002), "Building the archives of the future: advances in preserving electronic records at the National Archives and Records Administration", Archivi \& Computer, Vol.12 No.1, pp.29-42.

Tourney, M.M. (2003), "Caging virtual antelopes: Suzanne Briet's definition of documents in the context of the digital age", Archival Science, Vol.3 No.3, pp.291-311.

Tyler, D. (2003), "A grain of truth", Document Manager, Vol.11 No.1, pp.27-9.

UK Government (2001), E-government Policy Framework for Electronic Records Management, http://collections.europarchive.org/tna/20080107231552/http://www.nationalarchives.gov.uk/documents legov_framework.pdf.

Upward, F. (2000), "Modelling the continuum as paradigm shift in recordkeeping and archiving processes and beyond: a personal reflection", Records Management Journal, Vol.10 No.3, pp.115-39.

Urton, G. (1998), "From knots to narratives: reconstructing the art of historical record keeping in the Andes", Ethnohistory, Vol.45 No.3, pp.409-38.

Walden, I. (1993), "Electronic documentation and the law", in Ross, S. and Higgs, E. (Eds.), Electronic Information Resources and Historians: European Perspectives, Scripta Mercaturae Verlag, St Katharinen. Weinberger, D. (1996), "What's a document?", Wired, August,

http://www. wired.com/wired/archive/4.08/document.html. Wilkins, J. (2009), E-mail to RECMGMT-L listserv, 21 May.

Yeo, G. (2007), "Concepts of record (1): evidence, information, and persistent representations", American Archivist, Vol.70 No.2, pp.315-43.

Yeo, G. (2008a), "Concepts of record (2): prototypes and boundary objects", American Archivist, Vol.71 No.1, pp.118-43.

Yeo, G. (2008b), Records and Representations, http://www.mybestdocs.com/yeo-g-recs-reps080410.pdf. 